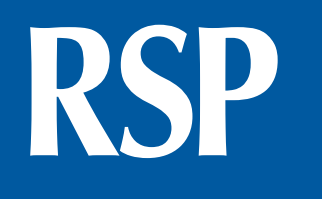

http://www.rsp.fsp.usp.br/
Revista de Saúde Pública

\title{
Cárie e água fluoretada em dois municípios brasileiros com baixa prevalência da doença
}

\author{
Mariângela Guanaes Bortolo da Cruz', Paulo Capel Narvai" \\ I Universidade de São Paulo. Faculdade de Saúde Pública. São Paulo, SP, Brasil \\ " Universidade de São Paulo. Faculdade de Saúde Pública. Departamento de Política, Gestão e Saúde. São \\ Paulo, SP, Brasil
}

\section{RESUMO}

OBJETIVO: Analisar a associação entre a exposição à água fluoretada e cárie dentária, em contexto de uso generalizado de creme dental fluoretado no Brasil, em cenário de baixa prevalência da doença.

MÉTODOS: Realizado estudo observacional transversal, de tipo censitário, na modalidade de duplo inquérito epidemiológico populacional, em dois municípios paulistas em 2014. Participaram adolescentes de 11 e 12 anos, imersos na sua condição de exposição $(n=184)$ ou não exposição ( $\mathrm{n}=128)$ à água fluoretada, há pelo menos cinco anos. As populações avaliadas residiam em comunidades da mesma região geográfica, de pequeno porte demográfico e com classificação socioeconômica similar, diferenciando-se apenas pela condição de exposição à água fluoretada (Silveiras) e de não exposição (São José do Barreiro). A experiência, a magnitude e o grau de polarização da cárie dentária nessas populações foram analisadas por meio dos índices CPOD e $\mathrm{SiC}$ e a associação foi testada empregando-se as estatísticas qui-quadrado de Pearson e razão de prevalência entre não expostos e expostos à água fluoretada.

RESULTADOS: Embora a experiência de cárie (CPOD $\geq 1)$ não tenha se associado com a exposição à água fluoretada (qui-quadrado $=1,78 ; \mathrm{p}=0,18 ; \alpha=5 \%$ ), observou-se expressiva diferença na magnitude com que a doença atingiu a população: as médias CPOD foram de 1,76 em expostos e 2,60 em não expostos e as médias $\mathrm{SiC}$ foram de 4,04 e 6,16, respectivamente. $\mathrm{O}$ grau da polarização, indicado pela porcentagem de indivíduos com $\mathrm{CPOD}=0$, foi diferente, maior (41,8\%) em expostos e menor (34,3\%) em não expostos. A razão de prevalência entre não expostos e expostos foi de 1,13, indicando pouca expressividade na diferença das prevalências.

CONCLUSÕES: A exposição à água fluoretada implicou menores valores médios dos índices CPOD e SiC, ainda que em presença de exposição concomitante a dentifrício fluoretado, em cenário de baixa prevalência da doença e padrão similar de distribuição de cárie nas populações analisadas.

DESCRITORES: Fluoretação. Cárie Dentária, prevenção \& controle. Índice CPO. Saúde Bucal Estudos Transversais.

Copyright: Este é um artigo de acesso aberto distribuído sob os termos da Licença de Atribuição Creative Commons, que permite uso irrestrito, distribuição e reprodução em qualquer meio, desde que o autor e a fonte originais sejam creditados.

Correspondência:
Mariângela Guanaes Bortolo da Cruz Rua Roquete Pinto, 313 Butantã 05515010 São Paulo, SP, Brasil Recebido: 2 mar 2017

Como citar: Cruz MGB, Narvai PC. Cárie e água fluoretada em dois municípios brasileiros com baixa prevalência da doença. Rev Saude Publica. 2018;52:28.

\section{(⿶)}




\section{INTRODUÇÃO}

Não há dados que comprovem que a fluoretação das águas de abastecimento público agregue benefício preventivo à cárie dentária aos proporcionados pelo uso generalizado dos cremes dentais fluoretados em municípios de pequeno porte demográfico e baixa prevalência da doença no Brasil. A cárie dentária é o principal problema de saúde bucal em todo o mundo, sobretudo nos países em desenvolvimento ${ }^{12}$. Sua distribuição populacional heterogênea não decorre apenas de variações biológicas individuais, provenientes da relação "parasitahospedeiro", mas, sobretudo, de diferenças sociais que caracterizam as pessoas e o contexto em que estão inseridas ${ }^{2,9}$. Estudos epidemiológicos que consideram o conceito de "espaço social"', ainda que apenas descritivos, podem contribuir para a tomada de decisão relacionada com políticas públicas.

A população brasileira é marcada por profundas desigualdades socioeconômicas e por iniquidades na distribuição da cárie. A ocorrência desigual da doença nos diferentes grupos populacionais gera situações em que um pequeno número de indivíduos acumula a maior carga. Esse fenômeno é denominado "polarização da cárie", bem caracterizado em estudos nacionais desde o final do século passado ${ }^{2,20}$.

Considerando a comprovada ação preventiva dos dentifrícios fluoretados, há justificado interesse em saber se a eficácia da fluoretação das águas de abastecimento público se mantém em contextos em que o uso desses produtos está generalizado ou se é neutralizada ou reduzida a níveis insignificantes ${ }^{15}$. Isso justifica a avaliação do significado preventivo da exposição à água fluoretada para o enfrentamento e controle da doença.

Os dentifrícios fluoretados, amplamente comercializados no País desde o final da década de 1980, e a fluoretação das águas pelos sistemas de abastecimento público, obrigatória por lei no Brasil desde 1974, são os principais métodos preventivos contra a cárie dentária ${ }^{21}$.

A fluoretação das águas é uma tecnologia de Saúde Pública que consiste, basicamente, na adição controlada de flúor até atingir concentração considerada eficaz na prevenção da cárie dentária. O poder preventivo dessa medida é dependente da manutenção e estabilidade dos teores de flúor dentro dos níveis adequados ${ }^{7,18,19,25}$. É considerada uma tecnologia tempo-dependente, pois deve haver exposição a concentrações adequadas, ininterruptamente, por pelo menos cinco anos para atingir seu máximo benefício ${ }^{10,14,17}$.

Revisão sistemática do início deste século com 214 estudos sobre fluoretação das águas constatou que esse método é eficaz para a prevenção da cárie dentária. Embora associado com níveis de fluorose dentária muito leve e leve, não está associado com outros eventos adversos ${ }^{16}$. Estima-se que seu poder preventivo esteja em torno de $40 \%$ a $70 \%$ em crianças, além de reduzir a perda dentária em adultos de $40 \%$ a $60 \%^{1}$.

Antunes et al. ${ }^{2}$, utilizando o Significant Caries Index (SiC), que traduz o impacto da cárie nos indivíduos mais afetados, em uma amostra de 18.718 estudantes paulistas, encontraram os valores de 5,8 para os expostos à fluoretação das águas e de 7,2 para os não expostos. A carga da doença no polo de maior ocorrência de cárie foi $24 \%$ menor entre os beneficiados pela fluoretação.

O Brasil é o segundo país em frequência absoluta em cobertura populacional por água fluoretada ${ }^{17}$. O Ministério da Saúde admite uma cobertura em torno de $60 \%$ da população brasileira, com profundas disparidades regionais ${ }^{3}$. Em 2010, $75 \%$ da população dos Estados Unidos recebiam água fluorada. Em 2009, no estado de São Paulo, Brasil, 93,5\% da população eram servidas pela fluoretação na rede pública, distribuída em 85,1\% dos seus 645 municípios. Dentre os municípios paulistas sem fluoretação, 99\% tinham menos de 50 mil habitantes ${ }^{1}$.

Mesmo comunidades sem fluoretação podem ter suas populações beneficiadas indiretamente por águas fluoradas. O fluoreto veiculado por meio de alimentos e bebidas produzidos em 
áreas fluoretadas é também ingerido por populações dessas comunidades. Isso as torna relativamente expostas e mostra o mecanismo difuso desse método. Esse fenômeno é definido como "efeito halo" ${ }^{8,20}$.

Considerando o cenário das macrorregiões brasileiras nas primeiras décadas do século XXI, notadamente o Sul e o Sudeste, de baixo índice CPOD (número médio de dentes permanentes cariados, perdidos e obturados), polarização da cárie, efeito halo e exposição às múltiplas fontes de fluoretos, torna-se relevante investigar se a exposição à água fluoretada ainda agrega algum benefício na prevenção da cárie, especialmente aos mais suscetíveis à doença.

O objetivo deste estudo foi analisar a associação entre a magnitude da experiência de cárie dentária na dentição permanente e a exposição à água de abastecimento público fluoretada, em contexto de uso generalizado de creme dental fluoretado.

\section{MÉTODOS}

Estudo observacional transversal, de tipo censitário, na modalidade de inquérito epidemiológico populacional duplo, simultâneo. Os dados primários foram obtidos em 2014, nas faixas etárias de 11 e 12 anos, imersas na sua condição de exposição $(n=184)$ ou não exposição $(\mathrm{n}=128)$ à água fluoretada, há pelo menos cinco anos.

O desenho metodológico preferível para analisar a associação entre cárie dentária e fluoretação das águas deveria contemplar dois espaços sociais ${ }^{6}$ passíveis de comparações, com coleta simultânea de dados, compatíveis com o conceito de ensaio comunitário. Deveriam ser pareados por suas características de similaridade enquanto espaços sociais, em que apenas a exposição ou não à fluoretação das águas de abastecimento público, por pelo menos cinco anos, pudesse distingui-los. Essa opção metodológica decorre da recomendação de Barata e Werneck. Para eles, estudos epidemiológicos que focalizam cenários geográficos devem ampliar o conceito físico de território, compreendendo-o, sobretudo, como um "espaço social", ou seja, como construções sociais resultantes da ação humana organizada em sociedade, atuando sobre determinada paisagem ${ }^{6}$. Por essa razão, foram selecionados dois municípios que atendiam plenamente ao requisito de se constituírem em "espaços sociais" símiles, pareados a priori. Portanto, eram passíveis de gerarem parâmetros populacionais obtidos por meio de dois censos simultâneos, comparáveis diretamente.

O primeiro procedimento metodológico foi a investigação do histórico da fluoretação de todos os 645 municípios paulistas nos Sistemas Nacional e Estadual de Informação de Vigilância da Qualidade da Água para Consumo Humano no período de sete anos, de janeiro de 2008 a dezembro de 2014. Essas informações para os dois municípios selecionados foram conferidas a partir da averiguação dos laudos $(\mathrm{n}=128)$ das análises laboratoriais das amostras de água das coletas realizadas para fins de vigilância sanitária.

Para aferir o atendimento ao critério de exposição ou não à fluoretação das águas de abastecimento público, foi adotado o requisito de que pelo menos $80 \%$ dos resultados das análises estivesse de acordo, ou em desacordo, com as Resoluções SS 250/1995 ${ }^{23}$ e SS 65/2005 24 . Essas resoluções estabelecem que os teores de flúor nas águas da rede de abastecimento no estado de São Paulo podem variar de 0,6 a 0,8 mg F/L para que a população seja considerada beneficiada por níveis ótimos.

Dentre os municípios que atendiam e que não atendiam aos critérios de exposição à fluoretação e cujos espaços sociais cumprissem a exigência de similitude adotada neste estudo, os dois que mais bem se ajustaram do ponto de vista socioeconômico, incluindo aspectos culturais, foram identificados como: Silveiras (com fluoretação) e São José do Barreiro 
(sem fluoretação). Ambos eram localizados na região administrativa de Guaratinguetá, no Vale do Paraíba (Tabela 1).

A unidade de captação hídrica para tratamento da água e abastecimento da população é a Bacia do Rio Paraíba do Sul em ambas as cidades. Em São José do Barreiro, o gestor do sistema municipal de saneamento é o Departamento de Águas e Esgoto Municipal (DAE) e em Silveiras, é a Companhia de Saneamento Básico do Estado de São Paulo (Sabesp).

A etapa metodológica subsequente foi buscar a comprovação da exposição e da não exposição dos indivíduos, considerando a característica de estudo ecológico misto do delineamento. Para isso, o mapa da rede pública de abastecimento de Silveiras foi obtido junto à Sabesp. Toda a área urbana e grande parte da área rural recebiam água tratada e adequadamente fluoretada, à exceção de um pequeno bairro rural (Sítio Bom Jesus), cujos indivíduos não integraram o presente estudo. O mapeamento também foi realizado em conjunto com o DAE de São José do Barreiro, comprovando-se que suas águas não eram fluoretadas. Dessa forma, foi possível classificar os indivíduos como expostos ou não, aplicando-se o critério de pelo menos cinco anos de residência no mesmo município e local. A admissibilidade da exposição decorreu das características de sua compulsoriedade pelas populações nas localidades em que a tecnologia da fluoretação das águas de abastecimento público é empregada, não sendo possível admitir a não exposição dos indivíduos nesses espaços sociais.

O pareamento a priori, por similitude de espaços sociais das populações expostas e não expostas, foi assegurado pelo emprego de dois índices compostos: o Índice de Desenvolvimento Humano Municipal (IDHM) e o Índice Paulista de Responsabilidade Social (IPRS). Os valores desses indicadores para cada município permitem identificar espaços sociais com características extremamente similares (Tabela 1). Ademais, tal semelhança é confirmada pelas posições

Tabela 1. Características socioeconômicas dos municípios e qualidade da fluoretação da água de abastecimento público (Resoluções SS 250/1995 e SS 65/2005). Municípios de São José do Barreiro, Silveiras e estado de São Paulo, 2010 a 2016.

\begin{tabular}{|c|c|c|c|}
\hline \multirow{2}{*}{ Características socioeconômicas } & \multicolumn{2}{|c|}{ Município } & \multirow{2}{*}{ Estado de São Paulo } \\
\hline & São José do Barreiro & Silveiras & \\
\hline População em 2010 (a) & 4.077 & 5.792 & 41.262 .199 \\
\hline População em 2015 (b) & 4.185 & 6.158 & 44.396 .484 \\
\hline População em 2016 (c) & 4.183 & 6.193 & 44.749 .699 \\
\hline $\begin{array}{l}\text { Porcentagem da população na zona rural, } \\
\text { em } 2015\end{array}$ & 31 & 51 & 4 \\
\hline IDHM e IDH, em 2010 & 0,684 (médio) & 0,678 (médio) & 0,783 (alto) \\
\hline $\begin{array}{l}\text { Posição no ranking paulista do IDHM, } \\
\text { em } 2010(n=645)\end{array}$ & 617 & 625 & - \\
\hline IPRS, em 2012 & 5 (baixo) & 5 (baixo) & - \\
\hline $\begin{array}{l}\text { Abastecimento de água - nível de } \\
\text { atendimento pela rede pública em } \\
2010(\%)\end{array}$ & 98,8 & 97,6 & 97,9 \\
\hline $\begin{array}{l}\text { Número de análises laboratoriais } \\
\text { realizadas }(\mathrm{n}=128 \text { ) no período de } \\
\text { janeiro de } 2008 \text { a dezembro de } 2014 \\
\text { e seu respectivo percentual (\%) de } \\
\text { adequação segundo as Resoluções SS } \\
250 / 1995 \text { e SS } 65 / 2005\end{array}$ & $\begin{array}{c}\mathrm{n}=44 \\
(0 \%)\end{array}$ & $\begin{array}{l}\mathrm{n}=84 \\
(85,0 \%)\end{array}$ & - \\
\hline
\end{tabular}

IDHM: Índice de Desenvolvimento Humano Municipal; IDH: Índice de Desenvolvimento Humano; IPRS: Índice Paulista de Responsabilidade Social

Notas: (a) Censo IBGE 2010; (b) Estimada IBGE 2015; (c) Estimada IBGE 2016.

Fontes: IBGE 2016; Fundação SEADE 2017; PNUD 2017; SABESP 2017; Sistemas Nacional e Estadual de Informação da Qualidade da Água 2015; e Instituto Adolfo Lutz de Taubaté 2015. 
ocupadas por ambos no ranking do IDHM 2010 do Estado de São Paulo ( $\mathrm{n}=645)$, em que São José do Barreiro ocupa a posição 617 e Silveiras a de 625 (Tabela 1).

Silveiras e São José do Barreiro são também cidades que se assemelham nos aspectos ambientais e históricos. Extensas territorialmente com grandes áreas rurais, estão localizadas no antigo traçado da rodovia Rio-São Paulo, no Vale do Paraíba, região da Serra da Bocaina, estado de São Paulo. Ambas fundadas no final do século XVIII foram antigas áreas de cultivo de café e passagem de tropas, cidades ricas nos séculos XVIII e XIX, com populações superiores às atuais. Nos séculos XX e XXI, perderam relevância econômica e se transformaram em municípios que, empobrecidos, têm sua dinâmica econômico-social no pequeno comércio, pecuária, agricultura e turismo.

A distância entre Silveiras e São José do Barreiro é de 47 km e não há “invasão" de munícipes entre eles, ocorrência bastante comum em grandes centros urbanos e suas áreas metropolitanas conurbadas.

A coleta dos dados foi realizada por quatro equipes de examinadores e anotadores, compostas por cirurgiões-dentistas e auxiliares de saúde. O intervalo temporal entre a calibração das equipes e o trabalho de campo foi de três dias. As concordâncias interexaminadores $(\mathrm{K}=0,97-0,98)$ e intra-examinadores $(\mathrm{K}=0,98-1,00)$ foram consideradas ótimas, aferindo-se a consistência interna e externa das equipes ${ }^{25}$.

A coleta dos dados primários ocorreu em unidades escolares, sob boa iluminação e ventilação natural, e foi feita simultaneamente em ambos os municípios, em novembro de 2014. Adotaram-se critérios padronizados recomendados pela Organização Mundial da Saúde (OMS) para levantamentos epidemiológicos em saúde bucal ${ }^{26}$.

Todos os estabelecimentos de ensino existentes em ambos os municípios foram incluídos no delineamento, procurando-se examinar toda a população de 11 e 12 anos para análise da dentição permanente. A formação educacional em ambas as municipalidades era ofertada somente por instituições públicas em 2014. São José do Barreiro possuía seis escolas (duas urbanas e quatro rurais), enquanto Silveiras dispunha de quatro escolas (duas urbanas e duas rurais).

A exclusão escolar de quatro a 17 anos, segundo o censo IBGE 2010, era cerca de $10 \%$ nessas cidades. Por ocasião da coleta dos dados, essa informação foi conferida e ratificada pelos gestores municipais e estaduais de educação. $\mathrm{O}$ abandono aos estudos inicia-se gradativamente após os 14 anos, devido à necessidade de alguns adolescentes trabalharem para complementarem a renda de suas famílias. Também informaram que a totalidade da população aos 11 e 12 anos encontrava-se matriculada e frequentando rotineiramente as aulas.

As equipes procederam a retornos sistemáticos às escolas, conforme prevê o método, buscando esgotar as possibilidades de incluir todos os indivíduos. As perdas foram inferiores a 5\%, resultando, sobretudo, de recusas explícitas ou tácitas de pais ou responsáveis, e de faltas repetidas à escola. Assim, configurou-se o aspecto censitário deste estudo.

Questionários foram respondidos por pais ou responsáveis e aplicados conjuntamente com a realização dos exames bucais, contendo as variáveis: identificação da escola, responsável, examinado, idade, local e tempo de residência, fonte da água consumida, momentos de escovação dental, dentifrício utilizado, exposição a bochechos fluorados na escola e ensino de escovação.

Foram utilizados os índices CPOD e SiC. O índice CPOD pode ser definido como o número médio de dentes permanentes cariados, perdidos e obturados, em determinada idade, localizando-se a população no espaço e no tempo. É considerado um bom indicador das condições bucais: quanto menor o índice CPOD, melhor a situação de saúde bucal do indivíduo 
examinado ${ }^{3}$. Contudo, no atual contexto de polarização e baixa prevalência da cárie em que se encontra o Brasil, o índice CPOD proporciona uma visão por vezes incompleta da doença, principalmente em distribuições assimétricas.

O Significant Caries Index (SiC), proposto pela OMS em 2000, pode ser um instrumento epidemiológico auxiliar para a melhor caracterização da distribuição da cárie em populações. É calculado como a média CPOD do terço de indivíduos que apresenta a maior carga da doença (valores individuais mais altos de CPOD). Traduz, desse modo, o impacto da cárie nos indivíduos mais afetados e é útil para descrever cenários de polarização da doença ${ }^{22}$.

A fidedignidade das informações sobre exposição foi constatada pelo emprego da técnica de triangulação. Utilizaram-se como fontes: a) as populações participantes do inquérito; b) os gestores municipais responsáveis pelas políticas públicas de educação e saúde (secretários municipais, representantes regional e estadual de educação, diretores de escolas e professores), e; c) identificação e análise de documentos públicos oficiais. Essas fontes foram consultadas quanto à existência de programas ou estratégias preventivas em saúde bucal, como bochechos fluorados ou escovações supervisionadas, dentre outras, que poderiam ter sido executadas concomitantemente no período considerado neste estudo. Isto porque poderiam caracterizar-se em associação de métodos preventivos com interveniência nos desfechos analisados. Constatou-se que não foram realizadas atividades preventivas rotineiras em ambos os municípios, pelo menos nos últimos cinco anos. Toda a população pesquisada, exposta e não exposta à água fluoretada, escovava os dentes, ainda que irregularmente, pelo menos uma vez ao dia com dentifrício fluorado e essa foi a única fonte adicional de fluoretos a que os referidos indivíduos estiveram expostos no período considerado no estudo.

O processamento dos dados foi realizado empregando-se o software EpiInfo ${ }^{11}$. A magnitude da experiência de cárie nas populações expostas (E) e não expostas (NE) à fluoretação das águas foi avaliada por meio dos índices $\mathrm{CPOD}$ e $\mathrm{SiC}$. O dimensionamento da diferença entre as prevalências entre não expostos e expostos foi aferido por meio da razão de prevalência (RP) e a associação exposição-doença foi testada com o qui-quadrado de Pearson.

A pesquisa foi aprovada por Comitê de Ética por meio do processo CAAE 34299614.7.0000.5421, comprovante 064944/2014, reconhecido pelo sistema CEP/CONEP, respeitando-se os requisitos a esse tipo de investigação ${ }^{4}$.

\section{RESULTADOS}

O valor do índice CPOD foi de 1,76 (DP = 1,92) para os expostos à água fluoretada e de 2,60 $(\mathrm{DP}=3,38)$ para os não expostos (Tabela 2$)$.

Tabela 2. Índices SiC, CPOD e componentes aos 11 e 12 anos, segundo exposição à fluoretação das águas. Silveiras (com fluoretação) e São José do Barreiro (sem fluoretação), SP, 2014.

\begin{tabular}{|c|c|c|c|c|c|c|}
\hline \multirow{3}{*}{ Índice } & \multicolumn{6}{|c|}{ Exposição } \\
\hline & \multicolumn{3}{|c|}{$\operatorname{Sim}(n=184)$} & \multicolumn{3}{|c|}{ Não $(n=128)$} \\
\hline & $\mathbf{n}$ & Média & $\%$ & $\mathbf{n}$ & Média & $\%$ \\
\hline $\mathrm{SiC}$ & 63 & 4,0 & 100 & 43 & 6,2 & 100 \\
\hline CPOD & 323 & 1,8 & 100 & 333 & 2,6 & 100 \\
\hline Cariado & 89 & 0,5 & 27,6 & 287 & 2,2 & 86,2 \\
\hline Perdido & 7 & 0,1 & 2,1 & 7 & 0,1 & 2,1 \\
\hline Obturado & 227 & 1,2 & 70,3 & 39 & 0,3 & 11,7 \\
\hline
\end{tabular}

SiC: Significant Caries Index; CPOD: Número médio de dentes permanentes cariados, perdidos e obturados 
A moda foi 0,0 em ambas as distribuições e a mediana registrou 1,0 para os expostos e 2,0 para os não expostos. A amplitude de variação foi de nove para os expostos e 24 para os não expostos. O coeficiente de variação foi de 1,13 para os expostos e 1,30 para os não expostos.

O box plot da Figura 1 apresenta os padrões de variabilidade das duas populações, indicando visualmente a similaridade das dispersões e das tendências centrais nessas, em decorrência da baixa prevalência da doença. Mostra que as diferentes magnitudes representadas pelos valores do índice CPOD não decorreram da ocorrência de muitos valores aberrantes, uma vez que em ambas as distribuições houve ocorrência de apenas um valor com tal característica. Com efeito, a exclusão dos valores aberrantes das distribuições alterou minimamente as médias e os desvios-padrão, em níveis irrelevantes. As médias foram alteradas de 1,76 para 1,66 entre os expostos e de 2,60 para 2,43 entre os não expostos. As diferenças nas magnitudes praticamente mantiveram-se, declinando 1,3 pontos percentuais: de $47,7 \%$ com as distribuições completas para $46,4 \%$ para as distribuições sem os valores aberrantes. Os respectivos desvios-padrão registraram 1,92 e 3,38 nas distribuições completas e 1,84 e 2,81 nas distribuições sem os valores aberrantes. As diferenças nos desvios-padrão entre as distribuições de expostos e não expostos mantiveram-se e foram maiores para os não expostos em ambas as distribuições com e sem valores aberrantes.

O percentual de indivíduos sem experiência de cárie foi de 41,8\% em expostos e 34,3\% em não expostos (Figura 2).

Tanto expostos quanto não expostos apresentaram distribuições marcadas por moderada desigualdade interna (Figura 3). As curvas de Lorenz relativas aos expostos e não expostos corresponderam a Coeficientes de Gini de 0,5951 e 0,6158, respectivamente. Observou-se acentuada similaridade nos padrões de desigualdade de ambas as populações, mostrando que as diferentes magnitudes representadas pelos valores do índice CPOD não decorreram de diferenças nos padrões de desigualdades na ocorrência de cárie nessas populações.

A RP relacionando não expostos e expostos $(\mathrm{RP}=\mathrm{NE} / \mathrm{E})$ foi de 1,13 indicando pouca expressividade na diferença das prevalências. $O$ valor do qui-quadrado $(1,78 ; p=0,18 ; \alpha=5 \%)$ indicou que a diferença nas prevalências não pode ser atribuída à exposição à medida preventiva.

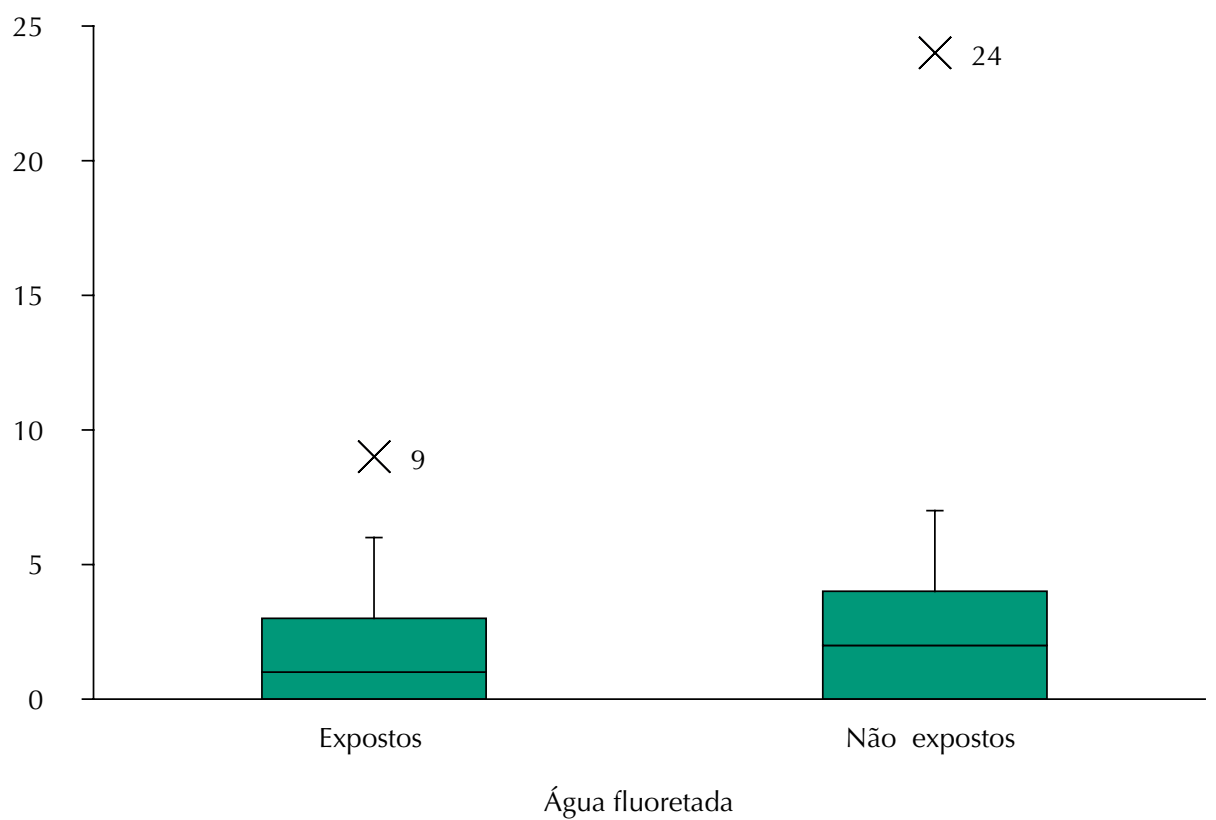

CPOD: número médio de dentes permanentes cariados, perdidos e obturados

Figura 1. Box Plot da distribuição dos valores do índice CPOD, em escolares de 11 e 12 anos, segundo exposição à água fluoretada. Silveiras (com fluoretação) e São José do Barreiro (sem fluoretação), SP, 2014 


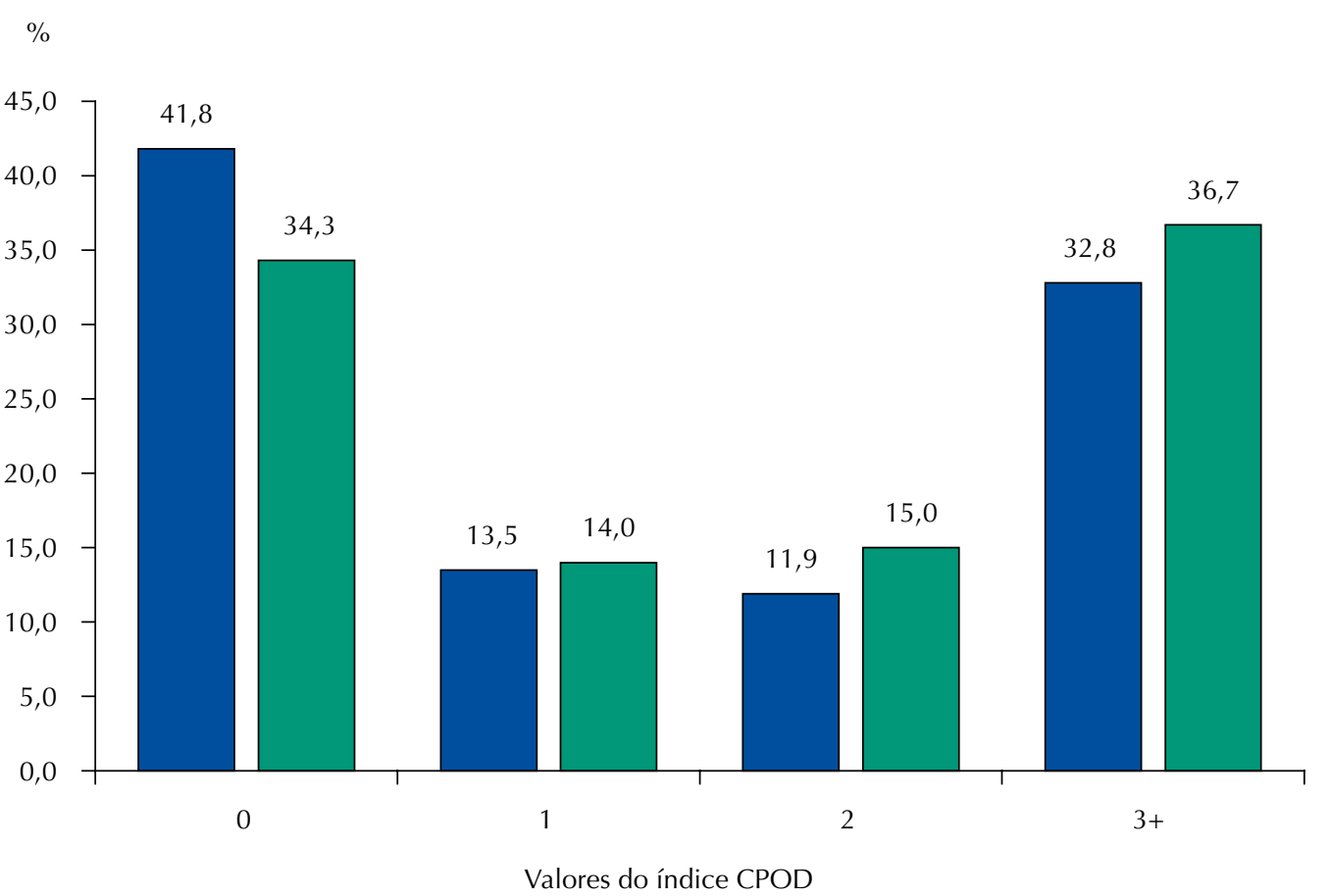

$\square$ Expostos $\square$ Não expostos

CPOD: número médio de dentes permanentes cariados, perdidos e obturados

Figura 2. Distribuição percentual dos valores do índice CPOD em escolares de 11 e 12 anos, segundo exposição à água fluoretada. Silveiras (com fluoretação) e São José do Barreiro (sem fluoretação), SP, 2014

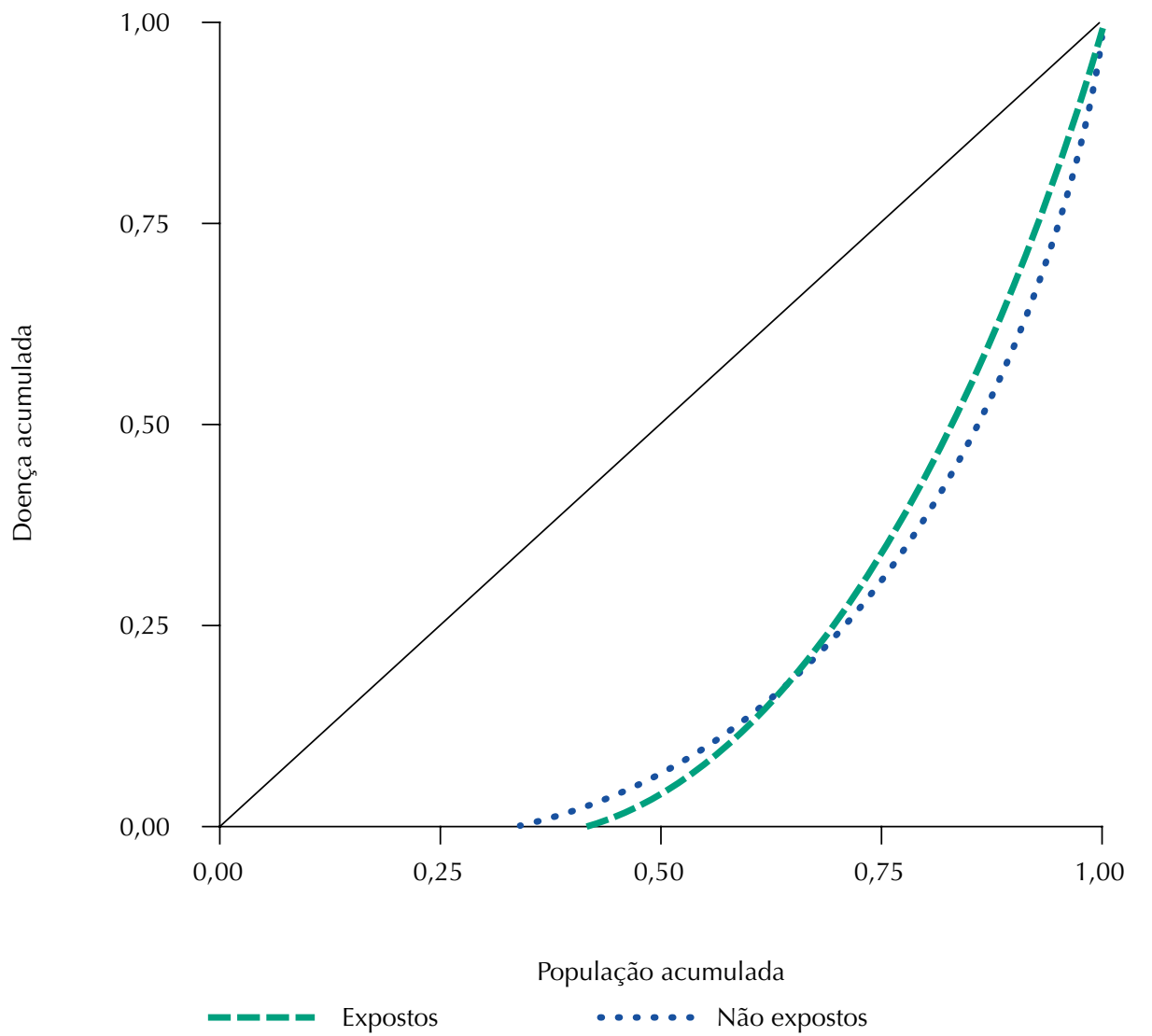

Figura 3. Curvas de Lorenz para as distribuições de carga de cárie dentária em escolares de 11 e 12 anos, segundo exposição à água fluoretada. Silveiras (expostos) e São José do Barreiro (não expostos), SP, 2014 


\section{DISCUSSÃO}

Em contextos epidemiológicos de baixa prevalência de cárie, em que a simples mensuração de prevalências pode ocultar diferenças relevantes no grau com que a doença se expressa em indivíduos e populações, é pertinente indagar sobre o impacto preventivo da fluoretação da água. Uma das possibilidades para avaliar esse aspecto é analisar a magnitude dos índices CPOD e SiC, pois tais instrumentos epidemiológicos possibilitam aferir essa dimensão para além das medidas tradicionais de incidência ou prevalência. Dentre os requisitos para avaliações desse tipo, a partir de dados obtidos em estudos transversais, incluem-se assegurar a similaridade das condições socioeconômicas de populações expostas e não expostas a serem comparadas e, além disso, a inexistência de diferenças significativas nas prevalências. Esta pesquisa, a primeira realizada no Brasil com essas características, é composta por dois censos populacionais epidemiológicos em populações diferenciadas apenas segundo a exposição ou não à fluoretação das águas de abastecimento público.

Estudos transversais têm limitações. Uma delas é o fato de recortarem a linha do tempo e não poderem, por essa razão, aferir simultaneamente o tempo de exposição a variáveis que podem estar associadas aos desfechos observados. Tais restrições aplicam-se a ensaios comunitários quando se pretende analisar intervenções de saúde pública e não se dispõe de registros obtidos anteriormente ao momento do corte transversal. Uma alternativa metodológica para atenuar limitações desse tipo é representada pela estratégia de realizar cortes concomitantes em populações comparáveis, em maior ou menor grau. Essa foi a estratégia adotada no presente estudo ${ }^{5,6}$.

Embora suas especificidades impeçam a extrapolação dos resultados, este trabalho foi executado em municípios de pequeno porte demográfico, cujas populações são inferiores a 10 mil habitantes. Tais qualificações configuram um cenário de estudo que os aproxima de condições demográficas semelhantes às encontradas em cerca da metade dos municípios brasileiros, segundo o IBGE ${ }^{13}$. Isso confere à análise, senão possibilidades de inferências estatísticas diretas, que seriam indevidas, algumas conotações que podem ser úteis a tomadores de decisão que se encontram em situações similares. Estudos transversais são delineamentos que podem ter grande utilidade no apoio à tomada de decisão envolvendo políticas públicas 5 .

A população sem experiência de cárie registra 7,5 pontos percentuais para menos entre os expostos em relação aos não expostos. Por sua vez, no polo de maior carga da doença (CPOD $\geq 3$ ), essa diferença em pontos percentuais registra 3,9 pontos percentuais para mais entre os não expostos à fluoretação. Tais valores correspondem a 21,9\% mais indivíduos sem experiência de cárie entre os expostos e a 11,9\% mais indivíduos com maior carga de doença (CPOD $\geq 3$ ) entre os não expostos. Esse dado confirma que essa medida preventiva segue produzindo efeitos relevantes no contexto do estudo no polo de maior carga da doença, embora as prevalências não sejam significativamente diferentes. Há polarização na distribuição do CPOD, tanto na população de expostos quanto na de não expostos à água fluoretada (Tabela 2 e Figura 2). Assim, as diferenças observadas entre essas populações ganham ainda maior relevância, pois está claramente em contexto epidemiológico de baixa prevalência de cárie e, ainda assim, o efeito preventivo proporcionado pela fluoretação das águas indica que essa medida é efetiva. O impacto é mais proeminente no polo de maior carga da doença.

O valor $(2,60)$ do índice CPOD obtido para os não expostos é 47,7\% maior do que o valor $(1,76)$ obtido para os beneficiados pela fluoretação das águas, ainda que ambas as populações tenham estado expostas aos fluoretos veiculados pelos cremes dentais nesses municípios. Ambos os valores do CPOD são classificados na categoria de baixa prevalência da doença pela OMS. Esta diferença (47,7\%), em contexto de comprovada exposição universal aos fluoretos contidos nos cremes dentais, representa uma informação original de enorme valor no contexto brasileiro, marcado por importantes desigualdades em saúde. Revela a persistência da potência preventiva da fluoretação da água, ainda que restrita ao âmbito do estudo. Este 
achado, inédito, sugere que seria relevante o potencial preventivo da fluoretação das águas de abastecimento público na maioria dos municípios brasileiros que não fluoretam, ainda que não se possa afirmar que alcançaria os $48 \%$ encontrados neste estudo. Por outro lado, é igualmente relevante o impacto da interrupção da fluoretação em municípios que vêm adotando essa medida preventiva, sobre os valores do índice CPOD. Tais admissões resultam dos conhecimentos disponíveis sobre a realidade demográfica e sanitária brasileira e de revisões sistemáticas sobre a eficácia da fluoretação da água, não derivando de inferência estatística deste estudo particular para a situação geral do país.

O índice $\mathrm{SiC}$ em expostos é de 4,04, enquanto para os não expostos é de 6,16 (Tabela 2). A não exposição à água fluoretada aumenta em cerca de $50 \%$ a média de dentes $\mathrm{CPO}$ entre os adolescentes que concentram a maior carga da doença. Este valor foi mais que o dobro do encontrado por Antunes et al., em 1998, quando essa diferença foi de $24 \%^{2}$.

A fluoretação das águas de abastecimento público foi identificada como uma variável ambiental com potencial para explicar a menor magnitude do índice CPOD entre expostos à medida no cenário de dois municípios brasileiros de pequeno porte demográfico, como o da maioria dos municípios do país nas primeiras décadas do século XXI. Isso é compatível com a teoria e as evidências científicas disponíveis. Ademais, no polo de maior carga da doença, ainda que em cenário epidemiológico de baixa prevalência da doença e mesmo na presença do uso cotidiano de creme dental fluoretado, a magnitude do índice $\mathrm{SiC}$ foi cerca de $50 \%$ menor do que o obtido entre os não expostos.

\section{REFERÊNCIAS}

1. Alves RX, Fernandes GF, Razzolini MTP, Frazão P, Marques RAA, Narvai PC. Evolução do acesso à água fluoretada no Estado de São Paulo, Brasil: dos anos 1950 à primeira década do século XXI. Cad Saude Publica. 2012;28 Supl:s69-80. https://doi.org/10.1590/S0102-311X2012001300008

2. Antunes JLF, Narvai PC, Nugent ZJ. Measuring inequalities in the distribution of dental caries. Community Dent Oral Epidemiol. 2004;32(1):41-8. https://doi.org/10.1111/j.1600-0528.2004.00125.x

3. Antunes JLF, Narvai PC. Políticas de saúde bucal no Brasil e seu impacto sobre as desigualdades em saúde. Rev Saude Publica. 2010;44(2):360-5. https://doi.org/10.1590/S0034-89102010005000002

4. Barbosa AS, Boery RNSO, Boery EN, Gomes Filho DL, Sena ELS, Oliveira AAS. A Resolução 196/96 e o sistema brasileiro de revisão ética de pesquisas envolvendo seres humanos. Rev Bioetica. 2011 [citado 3 nov 2017];19(2):523-42. Disponível em: http://revistabioetica.cfm.org. br/index.php/revista_bioetica/article/view/642

5. Barata RCB. O desafio das doenças emergentes e a revalorização da epidemiologia descritiva. Rev Saude Publica. 1997;31(5):531-7. https://doi.org/10.1590/S0034-89101997000600015

6. Barata RCB, Werneck GL. Observação e registro dos fenômenos epidemiológicos: tempo, espaço, indivíduos e populações. In: Almeida Filho NA, Barreto ML. Epidemiologia e Saúde: fundamentos, métodos e aplicações. Rio de Janeiro: Guanabara-Koogan; 2011. p.55-64.

7. Buzalaf MAR, Granjeiro JM, Damante CA, Ornelas F. Fluctuations in public water fluoride level in Bauru, Brazil. J Public Health Dent. 2002;62(3):173-6. https://doi.org/10.1111/j.1752-7325.2002.tb03440.x

8. Cangussu MCT, Narvai PC, Castellanos Fernandez R, Djehizian V. A fluorose dentária no Brasil: uma revisão crítica. Cad Saude Publica. 2002;18(1):7-15. https://doi.org/10.1590/S0102-311X2002000100002

9. Costa SM, Adelário AK, Vasconcelos M, Abreu MHNG. Modelos explicativos da cárie dentária: do organicista ao ecossistêmico. Pesq Bras Odontoped Clin Integr. 2012;12(2):251-91.

10. Cury JA. Uso do flúor e controle da cárie como doença. In: Baratieri LN. Odontologia restauradora: fundamentos e possibilidades. São Paulo: Editora Santos; 2001. p.34-68.

11. Dean AG, Dean JA, Burton AH, Dicker RC. Epi Info: a general-purpose microcomputer program for public health information systems. Am J Prev Med. 1991;7(3):178-82. 
12. Frias AC, Narvai PC, Araújo ME, Zilbovicius C, Antunes JLF. Custo da fluoretação das águas de abastecimento público, estudo de caso - Município de São Paulo, Brasil, período de 1985-2003. Cad Saude Publica. 2006;22(6):1237-46. https://doi.org/10.1590/S0102-311X2006000600013

13. Instituto Brasileiro de Geografia e Estatística, Diretoria de Pesquisas, Coordenação de População e Indicadores Sociais, Gerência de Estudos e Análises da Dinâmica Demográfica. Estimativa da população 2015. Rio de Janeiro: IBGE; 2015.

14. Kozlowski FC, Pereira AC. Métodos de utilização do flúor sistêmico. In: Pereira AC, organizador. Odontologia em saúde coletiva. Porto Alegre: Artmed; 2003. p.265-74.

15. Kumar JV. Is water fluoridation still necessary? Adv Dent Res. 2008;20(1):8-20. https://doi.org/10.1177/154407370802000103

16. McDonagh MS, Whiting PF, Wilson PM, Sutton AJ, Chestnutt I, Cooper J, et al. Systematic review of water fluoridation. BMJ. 2000;321(7265):855-9. https://doi.org/10.1136/bmj.321.7265.855

17. Ministério da Saúde (BR), Secretaria de Atenção à Saúde, Departamento de Atenção Básica. Guia de recomendações para o uso de fluoretos no Brasil. Brasília (DF); 2009 [citado 3 nov 2017]. (Série A. Normas e Manuais Técnicos). Disponível em: http://189.28.128.100/dab/docs/ portaldab/publicacoes/guia_fluoretos.pdf

18. Murray JJ. O uso correto de fluoretos na saúde pública. São Paulo: Editora Santos; 1992 [citado 3 nov 2017). (Série A. Normas e Manuais Técnicos). Disponível em: http://189.28.128.100/dab/ docs/portaldab/publicacoes/guia_fluoretos.pdf

19. Narvai PC. Cárie dentária e flúor: uma relação do século XX. Cienc Saude Coletiva. 2000;5(2):381-92. https://doi.org/10.1590/S1413-81232000000200011

20. Narvai PC, Frazão P, Roncalli AG, Antunes JLF. Cárie dentária no Brasil: declínio, iniquidade e exclusão social. Rev Panam Salud Publica. 2006;19(6):385-93. https://doi.org/10.1590/S1020-49892006000600004

21. Narvai PC, Frias AC, Fratucci MVB, Antunes JLF, Carnut L, Frazão P. Fluoretação da água em capitais brasileiras no início do século XXI: a efetividade em questão. Saude Debate. 2014;38(102):562-71. https://doi.org/10.5935/0103-1104.20140052

22. Nishi M, Bratthall D, Stjernswärd J. How to calculate the Significant Caries Index (SiC Index): without computers, with computers, with Internet. Malmö (SWE): WHO Collaborating Centre Faculty of Odontology, University of Malmö; 2001 [citado 3 nov 2017]. Disponível em: https:// www.mah.se/upload/FAKULTETER/OD/Avdelningar/who/MetodsIndices/SIC/data/significant.pdf

23. Secretaria de Estado da Saúde de São Paulo, Coordenação dos Institutos de Pesquisa, Centro de Vigilância Sanitária. Resolução SS 250, de 15 de agosto de 1995. Define teores de concentração de íon fluoreto nas águas para consumo humano, fornecidas por sistemas públicos de abastecimento. Diario Oficial Estado Sao Paulo. 16 ago 1995; Seção I.

24. Secretaria de Estado da Saúde de São Paulo, Coordenação de Controle de Doenças, Centro de Vigilância Sanitária. Resolução SS 65, de 12 de abril de 2005. Estabelece os procedimentos e responsabilidades relativos ao Controle e Vigilância da Qualidade da Água para Consumo Humano no Estado de São Paulo e dá outras providências. Diario Oficial Estado Sao Paulo. 13 abril 2005; Seção I:18.

25. Viegas AR, Viegas I, Castellanos RA, Rosa AGF. Fluoretação da água de abastecimento público. Rev Assoc Paul Cir Dent. 1987;41(1):202-4.

26. World Health Organization. Oral health surveys: basic methods. 4.ed. Geneva: WHO; 1997 [citado 3 nov 2017]. Disponível em: http://apps.who.int/iris/ bitstream/10665/41905/1/9241544937.pdf

Contribuição dos Autores: Concepção da pesquisa: MGBC, PCN. Coleta dos dados: MGBC. Análise e interpretação dos dados: MGBC, PCN. Elaboração e revisão do manuscrito: MGBC, PCN. Aprovação da versão final: MGBC.

Conflito de Interesses: Os autores declaram não haver conflito de interesses. 